Zuzana Judakova - Ladislav Janousek*

\title{
SOURCES OF ELECTROMAGNETIC FIELD IN TRANSPORTATION SVSTEM AND THEIR POSSIBLE HEALTH IMPACTS
}

Exposure to electromagnetic field caused by transportation systems is a cause of concern for many people. In public and personal transport there are many sources of electromagnetic field. Plenty of dosimetric analyses of electromagnetic field carried out by various research groups found out very high exposure values in the transport. Although the measured fields in transport remain well below the general limit for public exposure as defined by ICNIRP (1998) standards, they are relatively high compared to other micro-environments in daily life, especially for children seated in the rear seat, as field strengths are comparatively high there and children are a sensitive part of the population. How long-term effects of these fields affect the human organism and what is the mechanism of action, are questions without known answers. Several studies point to the potential association of various diseases with exposure to electromagnetic field. The key to understanding the effect of the electromagnetic field on the human organism is to reveal the mechanism of action of the field.

Keywords: Intelligent Transportation System, wireless communications, electromagnetic field, exposure, health impact

\section{Introduction}

The general public is exposed to an ever-increasing number of electromagnetic field (EMF) sources due to new infrastructure deployments, smart environments, novel wireless devices, various electric equipment and technologies (i.e., transmission lines, transformers, typical household appliances and their power supplies, public/personal transport and their technologies). Public/personal transport is a considerable source of EMF exposure.

Transport is a source of both low-frequency and highfrequency EMF. Sources of low-frequency EMF are various vehicle components requiring electric energy. Those components produce low-frequency EMF in the cables and components that conduct the electricity. The frequency range of such fields is wide, ranging from a few $\mathrm{Hz}$ to several $\mathrm{kHz}$. Electric and hybrid vehicles produce stronger EMF than traditional vehicles fitted with only petrol or diesel engines. The sources of high-frequency fields are various security systems to enhance passenger comfort, traffic efficiency, the safety of passengers and so on, by forwarding upcoming traffic information in a timely manner through wireless communication.

Exposure to electromagnetic field caused by the transportation system is a cause of concern for many people. Throughout the history of Earth's development (nearly 4 billion years), living organisms have been exposed to very low intensities of this type of radiation and therefore have not developed sufficient protection against electromagnetic radiation. The long-term effects of electromagnetic field can cause various health problems not only to people with electromagnetic hypersensitivity (EHS). To determine impact of electromagnetic fields on human health, it is needed to know values of EMF quantities. The quantities can be verified by dosimetric analyses and simulations.
The article summarizes EMF values in various microenvironment and links them to potential health risks.

\section{Sources of radiation in vehicles}

Today's cars typically have more than 50 electronic control units and many sensors that produce EMF (Figure 1) [1]. Almost all new cars on the market today contain at least some wireless inputs to these computers. It works with large volumes of vehicle driving history, including information technologies - navigation systems, telematics, emergency assistance systems, and remotecontrol locks to ensure greater driver safety.

Electronic dashboard is the basic source of high-frequency radiation in cars. Radio frequencies are used in a number of applications. The most commonly implemented technologies are: electronic security system, ad-hoc vehicle network (VANET), dedicated short-range communication (DSRC), GPRS / GSM / GPS localization systems, Bluetooth, Wi-Fi and other vehicle control systems.

Another problem may pose electric vehicles. In electric vehicles passengers sit very close to an electric system of significant power, usually for a considerable amount of time. The relatively high currents used in these systems and the short distances between the power devices and the passengers mean that the latter could be exposed to relevant magnetic field. It is considered necessary to perform a detailed analysis of the radiated EMF from electromotor and cables, in order to avoid exposure to not permissible limits. Due to the importance of the overall vehicle weight on the autonomy and performance characteristics, excessive shielding in cables of electric vehicles is not tolerated. This involve that it becomes requirement to evaluate

\footnotetext{
* Zuzana Judakova, Ladislav Janousek

Department of Electromagnetic and Biomedical Engineering, Faculty of Electrical Engineering and Information Technology, University of Zilina, Slovakia

E-mail: zuzana.judakova@fel.uniza.sk
} 


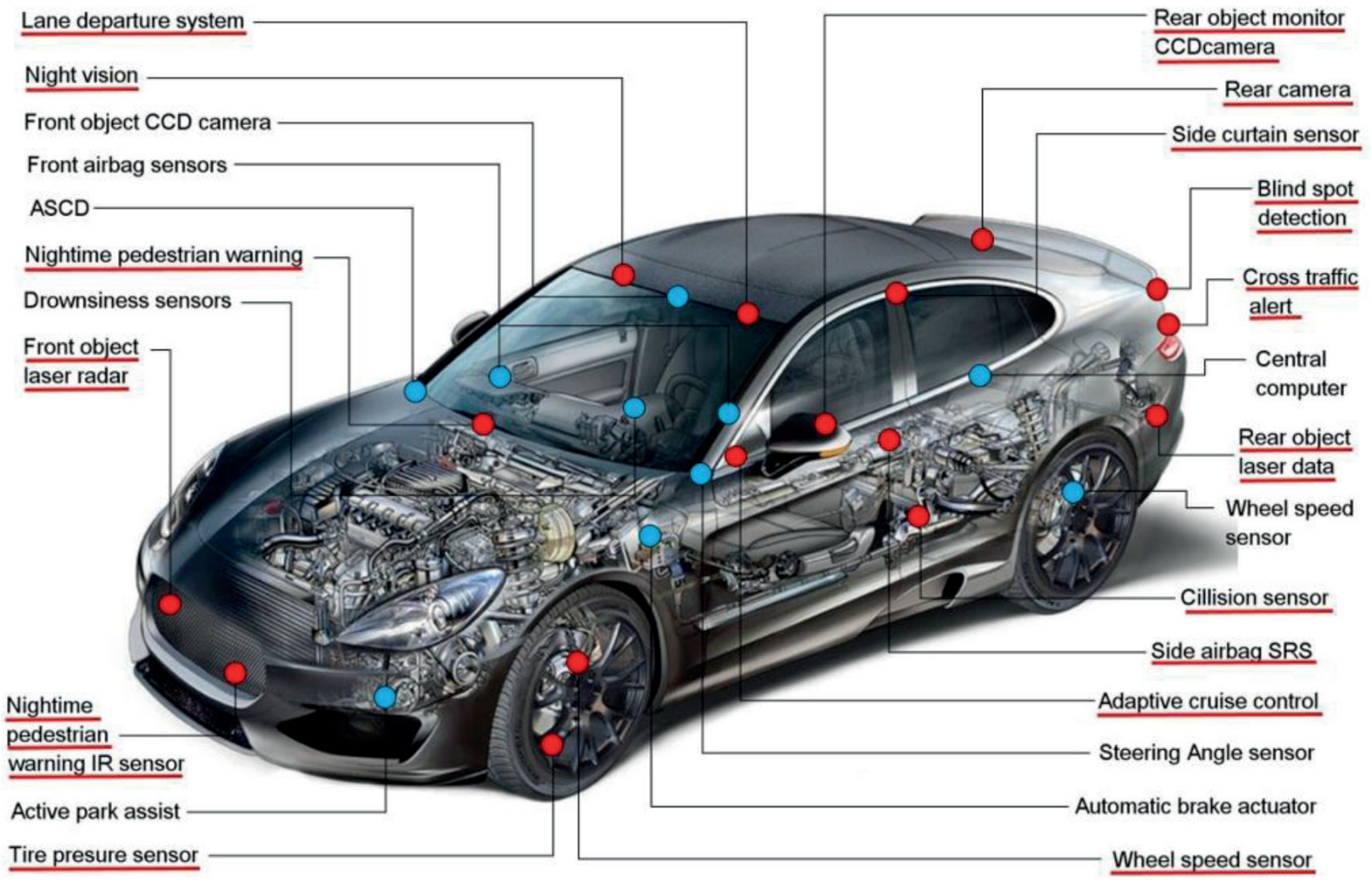

Figure 1 Radar and wireless sensors in car

the electromagnetic environment in the interior of these vehicles before placing them in the market [2].

Other major source of radiation that does not come directly from the vehicle but is very often used in vehicles is the cell phone. It transmits pulsed radio signals using the GSM mobile network (900-1800 MHz). Using mobile phone in partially closed environments of transportation vehicles, there are special situations for several reasons: the metallic structures produce large reflections, the structure itself is large compared to the wavelength, but the near field effects must be considered and the reflective surfaces are mostly curved. For whole body deposition, when the phone is far from the user, usage a cell phone inside a vehicle produces an increase of Specific Absorption Rate (SAR) values over the whole body. The vehicle structure is responsible for large relative changes in SAR [3].

\section{EMF values in various microenvironments}

Electricity is used substantially and sources of electromagnetic field are, unavoidably, everywhere. The transportation system is a source of the field, to which a large proportion of the population is exposed. In this part of the contribution the dosimetric analysis of EMF carried out by various research groups are summarized.

Eeftens et al. [4] collected simultaneous real-time personal measurements of radiofrequency electromagnetic fields (RFEMF) over 24 to $72 \mathrm{~h}$ in 294 parent-child pairs from Denmark, the Netherlands, Slovenia, Switzerland, and Spain. The devices measured the power flux density $\left(\mathrm{mW} / \mathrm{m}^{2}\right)$ in 16 different frequency bands every 4 seconds. Exposure during activities where most of the time is spent (home, school and work) was relatively low whereas exposure during travel and outside activities was higher. Figure 2 describe means of personal mean exposure to broadcast, DECT, downlink, uplink, and Wi-Fi per activity for children and parents. The total number of participants whose measurements contributed to each summary is shown, as well as the total number of measurement hours. The highest exposure values can be seen in the transport.

Measurements outside European countries were carried out by Choi et al. [5]. They monitored 50 child-adult pairs, living in Seoul, Cheonan, and Ulsan, South Korea. RF-EMF measurements were performed between September and December 2016, using a portable exposure meter tailored to capture 14 Korean radiofrequency bands ranging from 87.5 to $5875 \mathrm{MHz}$. The participants wear the device for $48 \mathrm{~h}$ and kept a time activity diary using a smartphone application in flight mode. To enhance accuracy of the exposure assessment, the body shadowing effect was compensated during the statistical analysis with the measured RF-EMF exposure. The compensation was transferred using the hybrid model that represents the decrease of the exposure level due to the body shadowing effect. The arithmetic (geometric) means of the total power density were $174.9(36.6) \mu \mathrm{W} / \mathrm{m}^{2}$ for all participants, 226.9 (44.6) for fathers, 245.4 (44.8) for mothers, and 116.2 (30.1) for children. By compensating for the body shadowing effect, the total RF-EMF exposure increased marginally, approximately 1.4 times. Among the three regions, total RF-EMF exposure was highest in Seoul, and among the activities, it was highest in the metro, followed by foot/bicycle, bus/car, and outside (Figure 3). Total RF-EMF exposure levels in Korea were higher than those reported in European countries.

The aim of the study [6] was to quantify RF-EMF exposure applying a tested protocol of RF-EMF exposure measurements using portable devices with a high sampling rate in 94 microenvironments and 18 public transport vehicles 


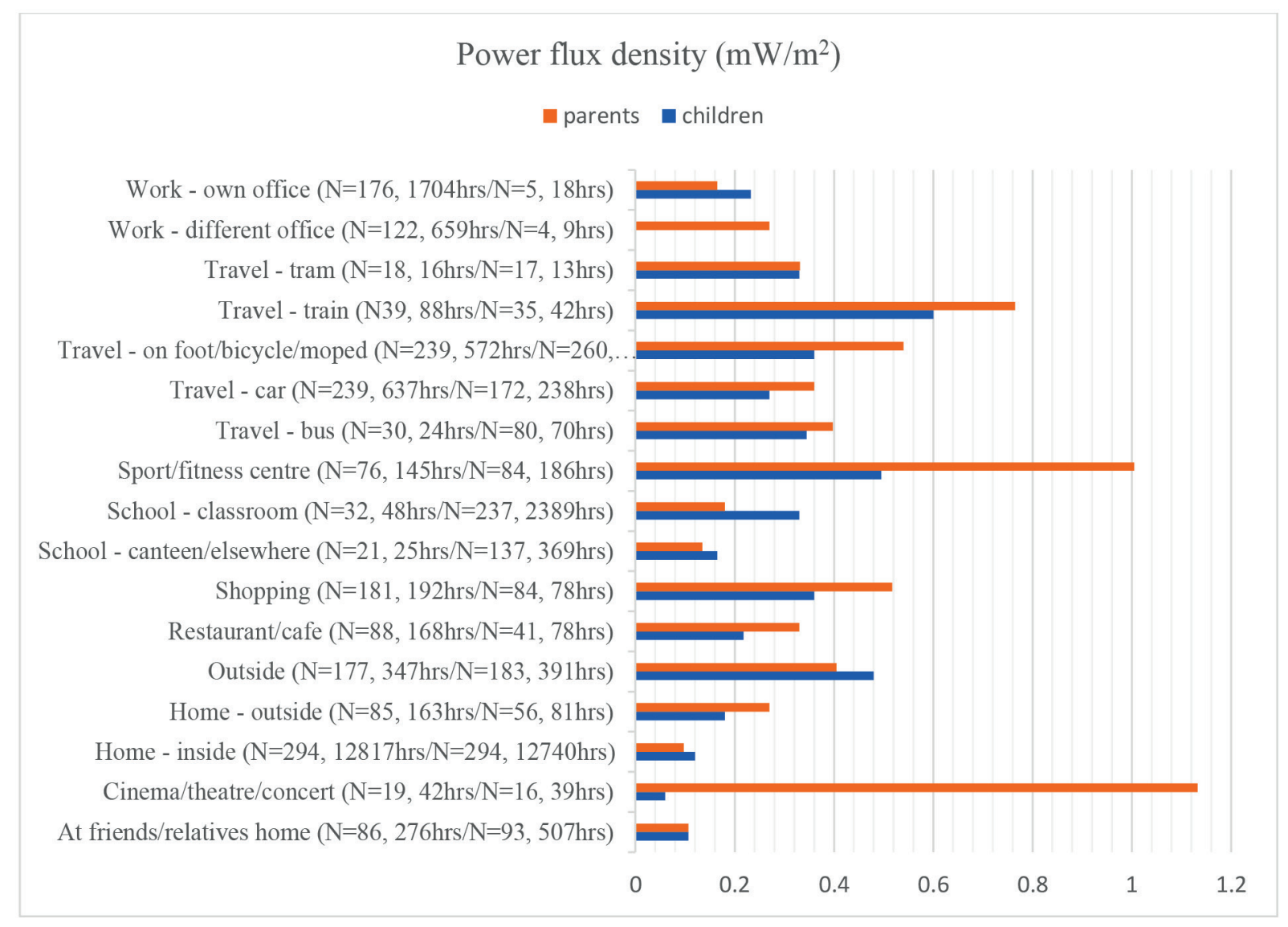

Figure 2 Means of personal mean exposure [4]

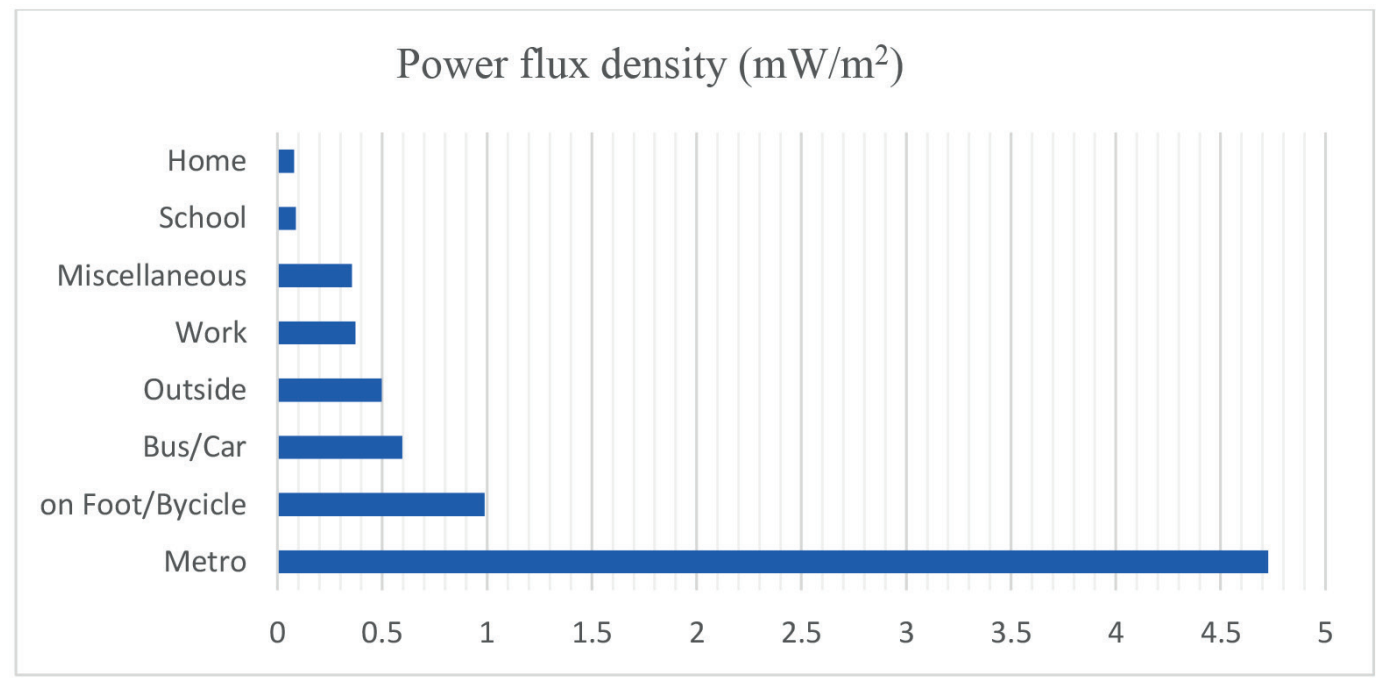

Figure 3 RF-EMF exposure levels by activities in Korean children and parents [5]

of Switzerland (15), Ethiopia (18), Nepal (12), South Africa (17), Australia (24) and the United States of America (8). The measurements were taken either by walking with a backpack with the devices at the height of the head and 20-30 cm from the body or driving a car with the devices mounted on its roof, which was $170-180 \mathrm{~cm}$ above the ground. The measurements were taken for about 30 min while walking and about 15-20 min while driving in each microenvironment, with a sampling rate of once every 4 seconds (ExpoM-RF) and 5 seconds (EME Spy 201). The highest RF-EMF exposure levels across public transportation were measured in auto rickshaw (Lalitpur, Nepal), taxi (Lalitpur, Nepal) and in train (Zurich, Switzerland) (Figure 4).

The main goal of study [7] is to determine the exposure level and spatial and temporal variances during 39 everyday activities in 12 frequency bands used in mobile telecommunication and broadcasting. Therefore, $24 \mathrm{~h}$ measurements were gathered from 98 volunteers living in or near Amsterdam and Purmerend, The Netherlands. They carried an activity diary to be kept to the minute, a GPS logger sampling at an interval of $1 \mathrm{~s}$, and an EME Spy exposimeter with a detection limit of $0.0066 \mathrm{~mW} / \mathrm{m}^{2}$ 


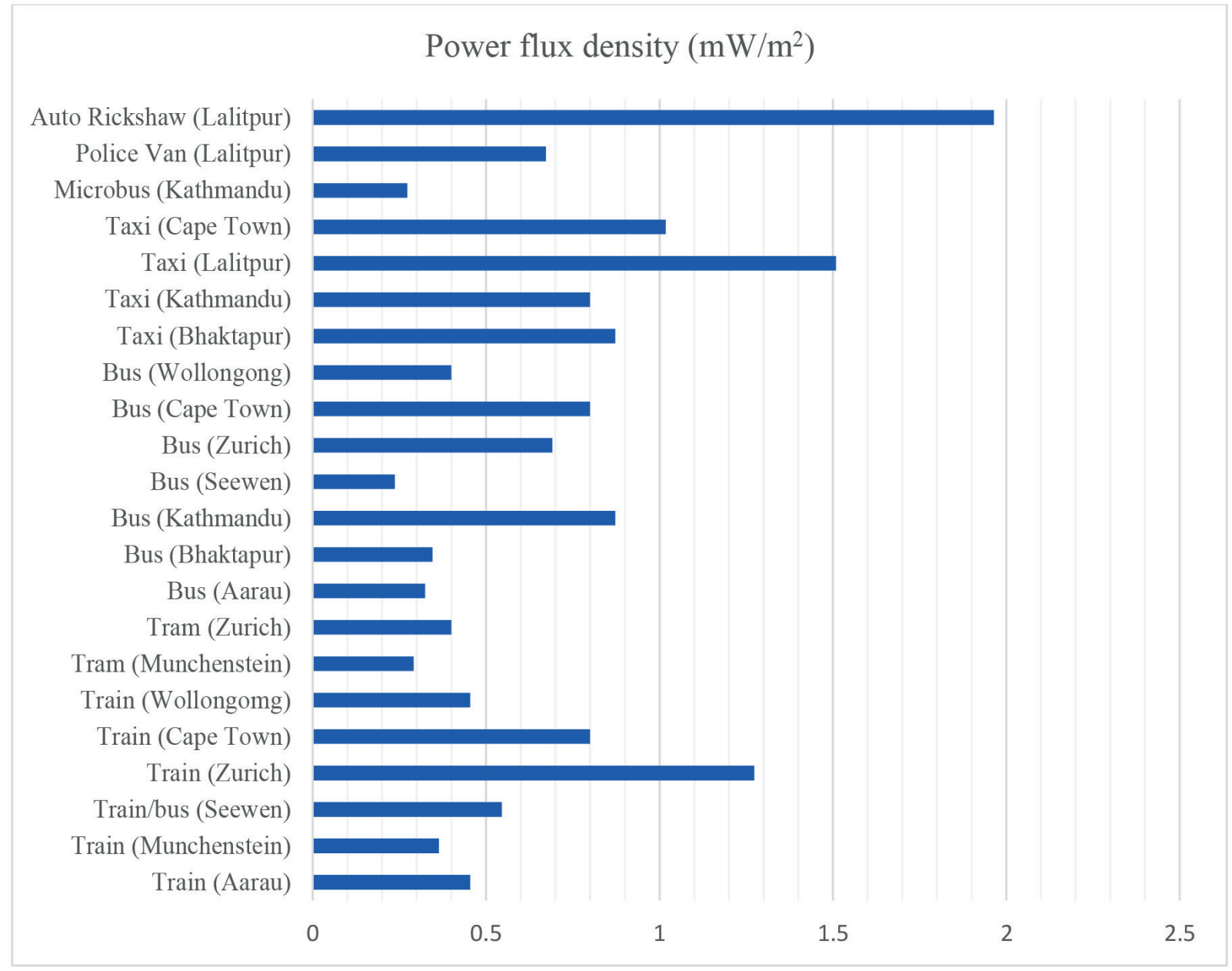

Figure 4 Mean RF-EMF exposure per type of microenvironment [6]

sampling at an interval of $10 \mathrm{~s}$ in 12 frequency bands. The mean exposure over $24 \mathrm{~h}$, excluding own mobile phone use, was 0.180 $\mathrm{mW} / \mathrm{m}^{2}$. The highest mean exposure relates to the activities with high people density, such as travelling by public transport, visiting social events, pubs or shopping malls. The highest exposure during public transport was from the GSM and DCS uplink bands $\left(0.162 \mathrm{~mW} / \mathrm{m}^{2}, 56.1 \% ; 0.048 \mathrm{~mW} / \mathrm{m}^{2}, 16.6 \%\right)$, but driving a car led to a higher exposure in case a passenger was calling $(0.314$ $\left.\mathrm{mW} / \mathrm{m}^{2}, 40.5 \% ; 0.381 \mathrm{~mW} / \mathrm{m}^{2}, 49.2 \%\right)$. At railway stations and bus/tram stops the highest contributors were the downlink bands. Travelling by tram led to higher exposure in the downlink bands than for other means of transport.

In work [8], RF-EMF exposure of 166 volunteers from Basel, Switzerland, was measured with personal exposure meters (exposimeters). Participants carried an exposimeter for 1 week (two separate weeks in 32 participants) and completed an activity diary. Mean values were calculated using the robust regression on order statistics (ROS) method. Mean weekly exposure to all RF-EMF sources was $0.13 \mathrm{~mW} / \mathrm{m}^{2}(0.22 \mathrm{~V} / \mathrm{m}$ ) (range of individual means $0.014-0.881 \mathrm{~mW} / \mathrm{m}^{2}$ ). Exposure was mainly due to mobile phone base stations (32.0\%), mobile phone handsets (29.1\%) and digital enhanced cordless telecommunications (DECT) phones (22.7 \%). Persons owning a DECT phone (total mean $0.15 \mathrm{~mW} /$ $\left.\mathrm{m}^{2}\right)$ or mobile phone $\left(0.14 \mathrm{~mW} / \mathrm{m}^{2}\right)$ were exposed more than those not owning a DECT or mobile phone $\left(0.10 \mathrm{~mW} / \mathrm{m}^{2}\right)$. Mean values were highest in trains $\left(1.16 \mathrm{~mW} / \mathrm{m}^{2}\right)$, airports $(0.74 \mathrm{~mW} /$ $\left.\mathrm{m}^{2}\right)$ and tramways or buses $\left(0.36 \mathrm{~mW} / \mathrm{m}^{2}\right)$, and higher during daytime $\left(0.16 \mathrm{~mW} / \mathrm{m}^{2}\right)$ than nighttime $\left(0.08 \mathrm{~mW} / \mathrm{m}^{2}\right)$. Mean RF-EMF exposure (power flux density) at different locations is showed in Figure 5. The hours indicate the total time of all study participants spent at each location.

In this study [9] measurements of electric and magnetic fields emitted from Australian trams, trains and hybrid cars in urban and suburban areas were investigated. Exposure values at the floor level and seat level were investigated. The magnetic field strength was measured at different points inside and near the moving train, trams and the hybrid car. Further conclusions that can be drawn from this work are: (1) magnetic field strength are higher in the front side (closer to driver's cabin) than the rear side of trams and trains; (2) when several trams or trains passed by, higher peaks in the fields occur; (3) the frequency and magnetic field strengths vary with speed and these are higher during acceleration; (4) magnetic field strength are higher at the rear side than at the front side of the hybrid car; (5) magnetic field strength are higher at the left side than at the right side of the hybrid car and (6) the maximum levels of recorded magnetic field strength are emitted at $50 \mathrm{~Hz}$ in the tram, $15.25-16.50 \mathrm{~Hz}$ in the train and $12 \mathrm{~Hz}$ in the hybrid car. Maximum of magnetic field was measured on rear left floor of hybrid car $-3.5 \mu \mathrm{T}$, on front floor of train $-8.7 \mu \mathrm{T}$ and on the middle floor of tram $-7.6 \mu \mathrm{T}$.

Stankowski et al. [10] measured alternating magnetic fields in a variety of different cars. Magnetic fields in cars in the $\mu \mathrm{T}$ 


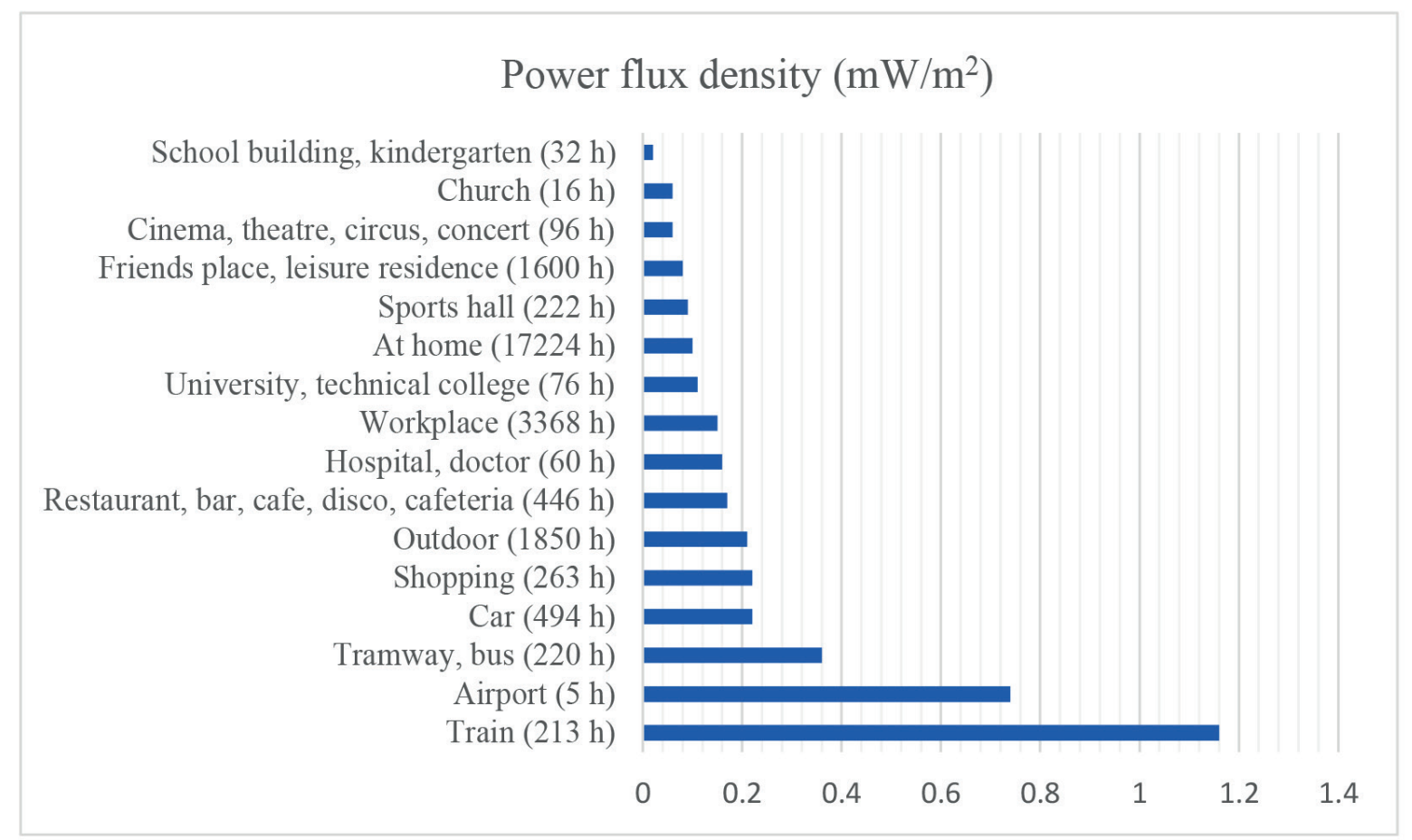

Figure 5 Mean RF-EMF exposure (power flux density) at different locations [8]

domain have been found to be produced by magnetized tires. In cars travelling at $80 \mathrm{~km} / \mathrm{h}$ originate low-frequency field. The magnetic fields were measured at frequencies from $5 \mathrm{~Hz}$ to 2 $\mathrm{kHz}$ in 12 different cars. Higher values were measured in the foot area of the passenger seat and on the back seat. In $33 \%$ of the cars, values above $2 \mu \mathrm{T}$ were measured; in $25 \%$ of the cars values were above $6 \mu \mathrm{T}$. The fundamental frequency of the magnetic fields is $10-12 \mathrm{~Hz}$ at a speed of $80 \mathrm{~km} / \mathrm{h}$. Considering the higher frequency harmonics, summed-up peaks reach values of up to $20 \mu \mathrm{T}$. Although the measured fields in cars remain well below the general limit for public exposure as defined by ICNIRP (1998) standards [11], they are relatively high compared to other exposures in daily life, especially for children seated in the rear seat, as field strengths are comparatively high there and children are a sensitive part of the population.

Presented research shows that humans are in modern world unavoidably exposed to considerable values of EMF. The highest values of the EMF power flux were measured in transport means. It should be noted that all the measured values are below limits given by the ICNIRP (1998). However, those limits are adjusted only based on the known thermal effects of EMF exposure. Those associated with the non-thermal phenomena are uncovered. Therefore, one should be aware that long-term exposure even to low level EMFs can lead to various health problems.

\section{Possible health impact}

Electromagnetic fields are packets of energy that have no mass. They fluctuate in frequency and wavelength. EMFs used for communications (RF-EMFs, $30 \mathrm{kHz}-300 \mathrm{GHz}$ ) and those generated by electricity (extremely low-frequency or ELF-EMFs, $3 \mathrm{~Hz}-3 \mathrm{kHz}$ ) do not have sufficient energy to directly cause ionization and are therefore known as non-ionizing radiation. RF-EMFs at sufficient intensity cause tissue heating.

Exposing frequency EMF greater than $\sim 100 \mathrm{kHz}$ can cause considerable energy absorption and increased temperature. In general, EMF exposure creates unequal energy storage in the body. Physical magnitude used to describe the absorption of electromagnetic field by living tissue is SAR. SAR should be minimized so that blood flow and other body heat distribution mechanisms can dissipate this heat. Thermal effects are associated with energy absorption, which causes an increase in the body temperature, with a significant increase in temperature being detected at the earliest after six minutes of exposure. In published data, the effects of heat are most often reported as damage to the inner ear, clouding of the eye lens and damage to the cornea as a result of eye warming.

The current subject of the investigation are secondary human health effects due to exposures to non-ionizing EMFs at low intensities that do not cause measurable heating. Thermal hazards are associated with acute exposures and are thought to be characterized by thresholds, below which they are not present. However, many studies have suggested that RF exposure at lower than thermal levels may have biological effects, but they have either not been consistently replicated or else their significance for human health cannot be adequately assessed using information currently available. Exposure to low frequency and radiofrequency electromagnetic fields at low intensities poses a significant health hazard. There is a strong proof that excessive exposure to mobile phone-frequencies over long periods of time enhance the risk of brain cancer both in humans and animals. Other possible consequences of exposure to EMFs are negative effects on male and female reproduction, risk for glioma, meningioma and acoustic neuroma, risk of leukemia among children (living near to very high intensity radio transmission towers), breast cancer, ipsilateral parotid tumors. There are other diseases or physiologic alterations 
which have been reported to be associated with exposure to non-thermal EMFs in humans and in animals: Alzheimer disease, increase neuropsychiatric and behavioral disorders, trigger cardiac rhythm alteration and peripheral arterial pressure instability, induce changes in immune system function and alter salivary and thyroid function, cognitive and neurobehavioral problems in children, idiopathic environmental intolerance. There is increasing evidence the exposures can result in neurobehavioral decrements and that some individuals develop a syndrome of EHS or microwave illness. While the symptoms are non-specific, new biochemical indicators and imaging techniques allow diagnosis that excludes the symptoms as being only psychosomatic. [12]

\section{Conclusion}

New technological developments during recent years are leading to the introduction of new sources of electromagnetic field. For example, inductive battery charging for electric cars (not only hybrids), are bearing exposure potential for occupants staying nearby, commonly implemented technologies than VANET or Bluetooth, and others present some future challenges for the exposure of the general population. Plenty of dosimetric analyses of electromagnetic field carried out by various research groups found out the highest exposure values in the transport. Drivers and passengers spend considerable amounts of time in these vehicles, and health risks might increase with the duration of exposure. We do not advocate going back to the age before electricity, wireless communication or transport without vehicles, but we want to show the possible adverse effects of EMFs on human health. It becomes requirement to evaluate the electromagnetic environment in the interior of vehicles before placing them in the market and before their daily application.

All measurement results presented in the paper show that the values are below the ICNIRP limits. However, it should be noted that those limits are adjusted, based only on the known thermal effects. Those associated with the non-thermal phenomena especially in case of long-term exposure are still uncovered. Critical amount of relevant data and exact mechanism/s of action are still missing concerning the non-thermal effects. It is thus recommended to use those technologies cautiously, especially by children. Children are a risk group because they are under development and therefore their organism is more susceptible to possible EM field effects.

\section{Acknowledgement}

This work was supported by project ITMS: 26210120021, co-funded from EU sources and European Regional Development Fund.

\section{References}

[1] GAJSEK, P., RAVAZZANi, P., GRElliER, J., SAMARAS, T., BAKOS, J., THUROCZY, G. Review of studies concerning electromagnetic field (EMF) exposure assessment in Europe: low frequency fields $(50 \mathrm{~Hz}-100 \mathrm{kHz})$. International Journal of Environmental Research and Public Health [online]. 2016, 13(9), p. 875. ISSN 1661-7827, eISSN 1660-4601. Available from: https://doi.org/10.3390/ijerph13090875

[2] MORENO-TORRES, P., LAFOZ, M., BLANCO, M., ARRIBAS, J. R. Passenger exposure to magnetic fields in electric vehicles. In: Modeling and simulation for electric vehicle applications [online]. 2016, IntechOpen, p. 47-71. ISBN 978-953-51-2637-9, eISBN 978-953-51-2636-2. Available from: https://doi.org/10.5772/64434

[3] ANZALDI, G., SILVA, F., FERNANDEZ, M., QUILEZ, M., RIU, P. J. Initial analysis of SAR from a cell phone inside a vehicle by numerical computation. IEEE Transactions on Biomedical Engineering [online]. 2007, 54(5), p. 921-930. ISSN 0018-9294, eISSN 1558-2531. Available from: https://doi.org/10.1109/TBME.2006.889776

[4] Eeftens, M., STRUChen, B., BIRKS, L. E., CARDis, E., ESTARliCH, M., FERnANDEZ, M. F., GAJSEK, P., GALLASTEGI, M., HUSS, A., KHEIFETS, L., MEDER, I. K., OLSEN, J., TORRENT, M., TRCEK, T., VALIC, B., VERMEULEN, R., VRIJHEID, M., VAN WEL, L., GUXENS, M., ROOSLI, M. Personal exposure to radio-frequency electromagnetic fields in Europe: Is there a generation gap? Environment International [online]. 2018, 121(1), p. 216-226. ISSN 0160-4120, eISSN $1873-6750$. Available from: https://doi.org/10.1016/j.envint.2018.09.002

[5] CHOI, J., HWANG, J.-H., LIM, H., JOO, H., YANG, H.-S., LEE, Y.-H., EEFTENS, M., STRUCHEN, B., ROOSLI, M., LEE, A.-K., CHOI, H.-D., KWON, J.h., HA, M. Assessment of radiofrequency electromagnetic field exposure from personal measurements considering the body shadowing effect in Korean children and parents. Science of The Total Environment [online]. 2018, 627, p. 1544-1551. ISSN 0048-9697, eISSN 1879-1026. Available from: https://doi.org/10.1016/j.scitotenv.2018.01.318

[6] SAGAR, S., ADEM, S. M., STRUCHEN, B., LOUGHRAN, S. P., BRUNJES, M. E., ARANGUA, L., DALVIE, M. A., CROFT, R. J., JERRETT, M., MOSKOWITZ, J.M., KUO, T., ROOSLI, M. Comparison of radiofrequency electromagnetic field exposure levels in different everyday microenvironments in an international context. Environment International [online]. 2018, 114, p. 297-306. ISSN 0160-4120, eISSN 1873-6750. Available from: https://doi.org/10.1016/j.envint.2018.02.036

[7] BOLTE, J. F., EIKELBOOM, T. Personal radiofrequency electromagnetic field measurements in the Netherlands: Exposure level and variability for everyday activities, times of day and types of area. Environment International [online]. 2012, 48, p. 133-142. ISSN 0160-4120, eISSN 1873-6750. Available from: https://doi.org/10.1016/j.envint.2012.07.006 
[8] FreI, P., MOHLER, E., NEUbAuER, G., THEIS, G., BURGI, A., FrOHLICH, J., BRAUN-FAHRLANDER, C., BOLTE, J., EGGER, M., ROOSLI, M. Temporal and spatial variability of personal exposure to radio frequency electromagnetic fields. Environmental Research [online]. 2009, 109(6), p. 779-785. ISSN 0013-9351, eISSN 1096-0953. Available from: https://doi.org/10.1016/j.envres.2009.04.015

[9] HalgamUGE, M. N., ABEYRATHNE, C. D. MENDIS, P. Measurement and analysis of electromagnetic fields from trams, trains and hybrid cars. Radiation Protection Dosimetry [online]. 2010, 141(3), p. 255-268. ISSN 0144-8420, eISSN 1742-3406. Available from: https://doi.org/10.1093/rpd/ncq168

[10] STANKOWSKI, S., KESSI, A., BECHEIRAZ, O., MEIER-ENGEL, K., MEIER, M. Low frequency magnetic fields induced by car tire magnetization. Health Physics. 2006, 90(2), p. 148-153. ISSN 0017-9078, eISSN 1538-5159.

[11] INTERNATIONAL COMMISSION ON NON-IONIZING RADIATION PROTECTION, VECCHIA, P., HIETANEN, M., MATTHES, R., AHLbOM, A., BREITBART, E., DE GRUIJL, F. R., FEYCHTING, M., GREEN, A., JOKELA, K., LIN, J., SAUNDERS, R., SCHUlMEISTER, K., SODERBERG, P., STUCK, B., SWERDlOW, A., TAKI, M., VEYRET, B., ZIEGELBERGER, G., REPACHOLI, M. H., ICNIRP ELF TASK GROUP, MATTHE, R., AHLBOM, A., JOKELA, P., ROY, C., SAUNDERS, R. Guidelines for limiting exposure to time-varying electric and magnetic fields (1 Hz to $100 \mathrm{kHz}$ ). Health Physics [online]. 2010, 99(6), p. 818-836. ISSN 0017-9078, eISSN 1538-5159. Available from: https://doi.org/10.1097/HP.0b013e3181f06c86

[12] BELPOMME, D., HARDELL, L., BELYAEV, I., BURGIO, E., CARPENTER, D. O. Thermal and non-thermal health effects of low intensity non-ionizing radiation: an international perspective. Environmental Pollution [online]. 2018, 242(A), p. 643-658. ISSN 0269-7491, eISSN 1873-6424. Available from: https://doi.org/10.1016/j.envpol.2018.07.019 